\title{
1. Behavioral economics and insurance: Principles and solutions
}

Howard C. Kunreuther and Mark V. Pauly

\section{INTRODUCTION}

It is easy for consumers to make mistakes in insurance markets, especially when deciding whether to purchase insurance against lowprobability, high-consequence (LP-HC) events. Consumers have a hard time collecting and processing information to determine the likelihood and consequences of these risks, with which (by definition) they have had limited or no experience. Hence, people often rely on feelings and intuition rather than careful thought when it comes time to decide what coverage to purchase.

On the supply side, insurance companies face the risk of experiencing large claims payments, only part of which can be spread or diversified away through the law of large numbers if losses are highly correlated. Decision makers in the insurance industry and those who regulate, litigate, and legislate about insurance are also likely to make mistakes for the same reasons that consumers do. They often rely on their intuition rather than undertaking deliberative thinking because they have limited information from past experience on which to base their decisions.

In this chapter we take a realistic but optimistic view of the prospects for improving the functioning of insurance markets. Our primary goal is to specify, explain, and justify principles for structuring and governing insurance markets to account for buyers and sellers who make mistakes, both cognitive and systematic, that lead to their failure to maximize expected utility or expected profits. A secondary goal is to propose market and regulatory structures in accordance with these principles.

We use two recent examples of legislation - the Biggert-Waters Act and the Affordable Care Act (ACA) - to illustrate how insurance could be redesigned to adhere to these principles much of the time, but not all the time. These public policies are intended to encourage consumers to purchase insurance that they ought to have, but often do not. We also consider other possible policies designed to correct systematic examples of people buying insurance at high premiums when deliberative decision making suggests that it would be more 
appropriate to go without coverage. We conclude by building on these examples to suggest future strategies involving the public and/or private sector.

\section{BEHAVIORAL ECONOMICS AND INSURANCE: CORE FINDINGS AND POLITICAL PROSPECTS}

According to insurance theory, those at risk benefit from incurring a small cost in the form of a premium to obtain protection against an event that could produce significant financial losses but that has a low probability of occurrence. If insurance can be offered with relatively small administrative costs, so it is reasonably priced, a risk-averse individual should prefer a smaller certain premium to taking the chance of experiencing a large loss (Arrow 1971). If properly designed and priced, insurance also offers incentives in the form of premium reductions for people who mitigate their risk in a cost-effective way, if the insurer can accurately incorporate the impact these mitigation measures will have on reducing the likelihood and/or consequences of events for which they offer financial protection (Shavell 1979).

There is considerable empirical evidence that many consumers fail to take advantage of insurance protection against losses of property and health, and do not invest in efficient loss reduction measures in the LP-HC setting. In both cases they fail to behave in ways that would not only benefit them personally ex ante, but might also enhance social welfare if there are societal concerns about people's ex post wellbeing. Behavioral economics offers some explanations for these decisions and suggests remedies. However, designing these solutions may require interventions by public and private institutions beyond just structuring information and options to take advantage of individuals' decision processes.

To illustrate this point, field and controlled experiments in behavioral economics reveal that consumers are sometimes more likely to select a default option rather than going to the trouble of opting out in favor of some other alternative. These findings have been used to encourage consumers to choose options that are in their best interests, such as better (dominant) 401(k) plans (Madrian and Shea 2001) and to adopt the 'Save More Tomorrow' plans that encourage consumers to earmark a portion of their increased earnings into these plans (Thaler and Benartzi 2004). Default options have also been used to increase the number of organ donations (Johnson and Goldstein 2003) and in other programs detailed in the important book, Nudge: Improving Decisions 
about Health, Wealth, and Happiness (Thaler and Sunstein 2008). To date, this framing technique has been applied to situations where the outcome is either known with certainty, or when the chosen option (such as a recommended $401(\mathrm{k})$ plan), has a higher expected return than the other options.

For decisions under uncertainty that involve insurance, the economic benefits of having coverage are reaped when the (low-probability) loss-producing event occurs and the claims payments are greater than the premiums paid by the buyer. If no loss occurs, the person would have been better off financially, after the fact, by not having purchased insurance. It is unlikely that people who failed to purchase insurance would reverse course if a loss did not occur, or purchase coverage without having suffered a loss even if insurance purchase was the default option.

In this regard, there is considerable empirical evidence that insurance behavior is guided by misperception of risk, and the use of simple but inappropriate heuristic decision rules. Many who do not purchase property and health insurance perceive the likelihood of a serious event to be below their threshold level of concern. Individuals are often unwilling to voluntarily buy insurance coverage against a particular risk until after experiencing a loss. Many who purchased a policy are likely to cancel it if they have not made a claim after several years because they consider their insurance purchase to be a poor investment decision (Kunreuther, Pauly, and McMorrow 2013).

Policymakers who value economic efficiency as a policy goal may choose to utilize more stringent policy tools, such as premium subsidies or mandatory coverage, to induce individuals to protect themselves when they should, according to insurance theory, have invested in protection. Mandating insurance against losses from LP-HC events, such as natural disasters or serious illnesses, can also be justified from the vantage point of social welfare if the majority of taxpaying citizens feel that those at risk should protect themselves financially before losses occur, rather than relying afterwards on federal disaster relief covered by taxpayers' money.

As noted above, two significant pieces of legislation in the last two years have recognized the biases and heuristics utilized by individuals at risk, and have taken steps to address them. The Biggert-Waters Act in July 2012 (112th Congress 2012) passed major reforms to the National Flood Insurance Program (NFIP) by recognizing that insurance premiums should reflect risk. It also authorized the Federal Emergency Management Agency (FEMA) to fund a study on the affordability of flood insurance, focusing on the role that means-tested vouchers (in the same spirit as food 
stamps) and other forms of subsidy could play. ${ }^{1}$ The ACA passed in 2010 (111th Congress 2010), initiated numerous reforms in health insurance to expand coverage. It imposes penalties if consumers do not buy coverage, while recognizing the need to make the purchase of insurance more feasible for low- and medium-income individuals. The ACA offers insurance to individuals and small groups through exchanges to be subsidized with means-tested tax credits. Both Acts encourage the adoption of risk reducing measures in ways that consumers might not voluntarily choose to do.

Other countries have also incentivized individuals to undertake protective measures and mandated the purchase of insurance against natural disasters and health risks. In the case of natural hazards, in France, New Zealand, and Spain, the government plays a key role by providing insurance coverage against all disasters and requiring those at risk to protect themselves with insurance (OECD 2008). With respect to health insurance, all developed countries other than the United States have achieved virtually universal coverage of catastrophic medically related expenses with a combination of subsidies and mandated penalties, financing premiums primarily through tax or tax-like instruments.

Even so, challenges to such universal requirements persist in all countries. Mandates usually permit exceptions (for higher income people, for non-citizens, for certain classes of risk or types of medical care). Inadequate subsidies lead some consumers to complain that their premiums are unaffordable. Public support for mandates in the US is still rather weak, and other countries are having second thoughts about some aspects of their programs. So it is clear that in a democracy, any normative theory will have to be modified so that the proposed programs are politically acceptable.

As higher premiums began to be phased in for some properties around the United States based on Biggert-Waters, many homeowners claimed that they would not be able to afford coverage and/or that they were being treated unfairly. In response, the Homeowner Flood Insurance Affordability Act of 2014 passed Congress with substantial support from both the House and Senate and was signed by the President in March 2014. The legislation eliminates or delays the implementation of many of the rate changes made in Biggert-Waters and highlights the importance of dealing with affordability issues by providing additional funding for a study by the National Research Council now underway on this topic and the first of two reports from the NRC Committee was published in the spring of 2015 (National Research Council 2015). 


\section{INTUITIVE THINKING BY CONSUMERS, INSURERS AND REGULATORS}

For LP-HC events such as natural disasters, terrorism or catastrophic health-related expenses, neither consumers, nor insurers or regulators, behave in accordance with the dominant normative theory of insurance. Instead, people seem to follow their intuitions. After a severe loss, insurers may withdraw from covering this risk because they focus on the losses from a worst-case scenario without adequately reflecting on the likelihood of this event occurring in the future. For example, following 9/11 most insurers refused to offer coverage against terrorism without considering the chances of a future terrorist attack (Kunreuther, Pauly and McMorrow 2013). State insurance commissioners sometimes restrict insurers from setting very high premiums that reflect risk, for example, for coastal property, in part to address equity and fairness issues, sacrificing efficiency in the process. Following the severe hurricanes of 2004 and 2005 in Florida, regulators resisted proposed rate increases, and the state-funded company, Citizens Property Insurance Corporation, filled the gap by providing relatively inexpensive insurance (Kunreuther and Michel-Kerjan 2011).

With all these challenges to decision making, consideration of some ways to improve the choice process may be helpful while recognizing the obstacles to changing behavior. If decision makers were to be more systematic and deliberative in their thinking when making choices under uncertainty, they would likely compare alternatives by estimating the likelihoods of different events occurring and their consequences, and make trade-offs between the expected costs and benefits of each alternative.

\section{BOX 1.1 INTUITIVE AND DELIBERATIVE DECISION MAKING}

\section{INTUITIVE THINKING, SYSTEM 1}

Operates automatically and quickly, with little or no effort and no voluntary control.

Uses simple and concrete associations, including emotional reactions or simple rules of conduct that have been acquired by personal experience with events and their consequences.

DELIBERATIVE THINKING, SYSTEM 2

Initiates and executes effortful and intentional abstract cognitive operations when needed.

Cognitive operations include complex computations and formal logic. 
The characterization of judgment and choice that distinguishes intuitive thinking from deliberative thinking builds on a large body of cognitive psychology and behavioral decision research. A recent summary has been provided by Daniel Kahneman in his stimulating book Thinking, Fast and Slow (Kahneman 2011) as detailed in Box 1.1.

Intuitive thinking often draws upon the experiences, expectations, goals and beliefs of the parties involved in the decision. Such sources and heuristics typically require far less effort than more detailed analysis of the trade-offs among the options. Even when decision makers make an effort to think carefully, the intuitive appeal of some heuristics implies that they still make mistakes. While intuitive processes often lead to reasonably good decisions, they do not work well for LP-HC events, either because of a decision maker's undue focus on a recent event or because individuals perceive the likelihood of an extreme event to be below their threshold level of concern.

Deliberative thinking with respect to assessing risks requires considerable time and attention and the use of decision tools such as probability estimation, Bayesian updating, and the use of formal logic. Consumers at risk would ideally decide whether to purchase insurance - and if so, how much coverage - by comparing the expected costs and benefits of a set of different alternatives available to them using models of choice such as expected utility theory (von Neumann and Morgenstern 1944) or decision analysis (Raiffa 1968). If insurance premiums reflected risk, and risk-averse households used these models (i.e., acted rationally), those facing a LP-HC event would purchase coverage as long as there were no budget constraints. If all consumers at risk (rather than just a fraction of them) undertook deliberative (System 2) thinking, then risk-based flood insurance and catastrophic health insurance coverage would be viewed as highly valuable and would be purchased by almost everyone.

\section{Consumer Behavior}

While intuitive perceptions of risk are relatively accurate over a broad range of situations where one has considerable experience, individuals are likely to deviate from expert assessments of unfamiliar risks that involve small probabilities and high degrees of uncertainty (Cutler and Zeckhauser 2004; Kunreuther, Pauly, and McMorrow 2013). These events are subject to the availability bias where the judged likelihood of an event depends on its salience (Tversky and Kahneman 1973). There is thus a tendency to ignore rare risks until after a disaster occurs.

This is a principal reason why individuals tend to purchase insurance 
only after a disaster and cancel their policies several years later when they have not suffered a loss and perceive the likelihood of a disaster as so low that they do not pay attention to its potential consequences. An in-depth analysis of the entire portfolio of the NFIP revealed that the median tenure of flood insurance was between two and four years while the average length of time in a residence was seven years (Michel-Kerjan, Lemoyne de Forges, and Kunreuther 2012). This behavior occurs even when homeowners are required to purchase flood insurance as a condition for a federally insured mortgage because financial institutions are not enforcing this regulation.

Rational risk-averse consumers should attach high value to insurance that protects them against losses which are large relative to their wealth. The relatively thin market for catastrophic health coverage is due to the unwillingness of a majority of buyers to pay a relatively small additional premium for essentially unlimited coverage. This may be the reason that 55 to 60 percent of private group insurance (which covers more than 90 percent of those with private insurance) contained some kind of lifetime cap on benefits before health reform, which prohibited such limits (Musco and Somers 2012). The choices to limit coverage of catastrophic health-related events for employment-based groups were generally made by employers or unions, not individual workers. These agents for the employees should have strong incentives to avoid such mistakes, but they still make them. This same mistake in insurance design has been made by the government for the public Medicare Part A plan, where there are limits for coverage of inpatient care in any one year.

Such coverage limits seem irrational given the low costs and high benefits of protection. In a large insurance plan, very few beneficiaries would reach the typical upper limit, usually in the millions of dollars. Those groups who self-insure could buy reinsurance at relatively low prices to cover the costs of these events. The incremental premium to remove such limits is very low - less than 1 percent of what the insurer is currently charging (PricewaterhouseCoopers 2009). For example, if health insurance costs $\$ 2,000$ a year, then removing the upper limit would add less than $\$ 20$ to the premium. And yet many consumers ended up with coverage that did not include this low cost of added protection. The recent reform legislation requires all new private health insurance contracts to eliminate such limits (Musco and Somers 2012).

\section{Insurer Behavior}

It is easy to understand how consumers make mistakes about insurance. Surprisingly, insurance managers, despite high levels of expertise 
and strong incentives to make logical decisions, also make errors with respect to situations where there is uncertainty or ambiguous information regarding the low probability risks they face. When insurers have limited data and limited past experience with extreme events, there is a tendency for them to engage in intuitive thinking when determining what coverage to offer against specific risks and how much to charge.

To illustrate, prior to the terrorist attacks of September 11, 2001, actuaries and underwriters, despite their mathematical expertise and experience, did not specify a price for protection against terrorism coverage nor did they exclude this coverage from their standard commercial policies. This implied that they were essentially covering this risk for the very modest add-on for unspecified events included in typical property insurance premiums. The failure to examine the financial risks associated with terrorism was surprising given the attempted bombing of the World Trade Center in 1993, the 1995 Oklahoma City bombing and other terrorist attacks throughout the world. This behavior by insurers is in the spirit of a 'safety-first' model originally proposed by Roy (1952) and applied to insurance by Commissioner James Stone of Massachusetts. He suggested that an underwriter who wants to determine the conditions for a specific risk to be insurable will focus on keeping the probability of insolvency below some threshold level of concern rather than trying to maximize expected profits (Stone 1973). From discussions with insurance underwriters today, this safety-first model still characterizes their behavior.

Following 9/11, most insurance companies completely changed course and refused to offer any coverage against terrorism, considering it to be an uninsurable risk despite increased buyer demand. The few who did provide insurance charged extremely high premiums (Wharton Risk Center 2005). Prior to these terrorist attacks, Chicago's O'Hare Airport had $\$ 750$ million of terrorism insurance coverage at an annual premium of $\$ 125,000$. After $9 / 11$, insurers offered the airport only $\$ 150$ million of coverage at an annual premium of $\$ 6.9$ million. The airport was forced to purchase this policy since it could not operate without coverage (Jaffee and Russell 2003). Golden Gate Park in San Francisco was simply unable to obtain terrorism coverage at any price (Smetters 2004).

If actuaries and underwriters had used the more formal models of choice that characterize deliberative (System 2) thinking for determining protection against these extreme events, they would have more accurately estimated the change in likelihood of future terrorist attacks in different parts of the country and their potential consequences. Insurers could then have determined what types and amounts of coverage they would want to offer and the prices they would have to charge so as to maximize their expected future profits based on their current portfolio of 
policies. It seems implausible to us that they would have concluded that the likelihood of terrorist attacks took such a large jump as to call for the kinds of premiums just described.

In contrast, private insurers have been willing to offer catastrophic coverage for health insurance; its absence usually reflects inadequate demand by consumers as discussed above. Because illnesses that are financially catastrophic for patients are uncorrelated, even health insurers of moderate size are not concerned about a large loss relative to their portfolio from a single person's high medical expense. In this case, a person's very expensive medical treatment is potentially catastrophic for the person, but one such event will not sink any health insurer of reasonable size - and these events rarely happen to more than a tiny fraction of any health insurer's portfolio of risks.

\section{Regulator Behavior}

Insurance regulators have aided Florida homeowners in hurricane-prone areas by keeping property insurance costs lower than they would be if private insurers were free to charge premiums that reflected risk. Following Hurricane Andrew in 1992, insurers were only allowed to raise rates gradually over the next decade and were restricted from canceling existing homeowners' policies. Moreover, political pressure from residents in hurricane-prone areas to reduce homeowners' premiums led the state legislature in 2007 to form a residual market mechanism, Citizens Property Insurance Corporation, which offers premiums at highly subsidized rates, thus undercutting the private market. Today, Citizens is the largest provider of wind coverage in Florida. There have been no severe hurricanes in the state since 2005, but if Citizens suffers a severe loss from a large hurricane in the coming years, it would likely become insolvent. In this case, Florida would have to levy a tax on its residents and potentially request disaster assistance from the federal government (Jaffee, Chapter 6 in this volume).

This example illustrates behavior triggered by apparent short-term intuitive thinking by regulators and legislators. (We cannot distinguish between cognitive flaws in regulators' minds and the political pressures to go along with cognitive flaws in voters' minds.) The strategy yields positive returns if there is no hurricane damage in Florida in the near future, but the current premium structure will lead to aggregate claims payments that exceed premiums in the long run. If regulators had undertaken a more systematic analysis of the long-term impacts of their behavior, they would not have formed Citizens in this manner by allowing it to charge highly subsidized premiums. They should have permitted insurers to charge 
premiums reflecting risk and found other ways to aid those residing in hurricane-prone areas needing special treatment. Just as low-income families are provided with food stamps to buy groceries, low-income residents could be given means-tested insurance vouchers so they can afford the higher risk-based premiums.

\section{CHALLENGES FOR MAKING POSITIVE CHANGES}

A key challenge in utilizing economic incentives to improve insurance choices is that these incentives may be viewed by some citizens as being unfair or inequitable. Suppose, for example, the house that a homeowner purchased years ago is now categorized as being in a floodplain, or a family's vacation cottage on the coast now faces a greater risk of hurricane damage due to climate change. At the time the property was bought, damage from hurricanes and floods was not considered a problem. Or suppose some people's current health status is adversely affected by past behavior or genetic disease propensities. Premiums that reflect their current property or health-related risk are likely to be viewed as unfair by the affected individuals because they feel the premiums are too high. But for insurance to operate efficiently, it is necessary for insurers to raise premiums for those now facing a higher likelihood of a property loss or illness. Insurers would then be in a position to charge lower premiums to those who have low expected claims, so that purchasing coverage is viewed as an attractive option for this group.

If premiums do not reflect the hazardous location of property or adverse genetic conditions, insurance will be ipso facto subsidized for these highrisk individuals. They will have less reason to undertake actions to reduce their risk if they are able to do so because they will not be rewarded with lower premiums. Failure to risk-rate premiums creates moral hazard. Another result will be that lower-risk consumers who undertake deliberative thinking will tend to purchase less insurance. In fact, they may avoid purchasing insurance altogether if premiums are set higher than they should be, perceiving insurance to be a bad buy. On the other hand, the high risks will insure even small losses because they consider coverage to be a bargain. This behavior will lead to problems of adverse selection. There is either inefficient exposure to risk or inefficient costs of processing small claims. The moral hazard distortion in incentives occurs when individuals can change behavior in ways that alter risk; the adverse selection distortion in insurance purchasing occurs regardless of whether risk variation is endogenous or exogenous.

In summary, insurance is a policy tool that has two principal purposes - 
encouraging cost-effective investment in loss reduction measures via premium reductions, and providing financial protection should those at risk suffer severe losses. A system of insurance where premiums are not risk based fails to address these two objectives effectively. Under such a system, insurers will have limited or no financial incentive to offer reductions in premiums to individuals who undertake loss reduction measures. In fact, insurers are losing money on these individuals in the long run and would prefer that they bought coverage elsewhere. Individuals who are not highly risk averse are unlikely to purchase coverage if they are charged a premium somewhat greater than their expected loss.

With respect to state regulation, insurance commissioners may feel compelled to restrict prices on those facing high risks because they rely on vocal consumers' support; their desire for re-election may override their concern for the common good (Pauly, Kunreuther, and Vaupel 1984).

To address these challenges we propose the following guiding principles for making insurance more transparent, understandable, and equitable, with the dual objectives of improving individual and social welfare.

Principle 1: Require insurance against rare catastrophic risks. Given the reluctance of individuals to voluntarily purchase insurance against losses that are large relative to their wealth or income, catastrophic coverage should be required for all individuals who face this risk, no matter how small its probability.

Principle 2: Premiums must reflect risk. Insurance premiums should accurately reflect risk to signal to individuals how safe and healthy they are, and to encourage individuals to undertake measures to reduce their vulnerability to illness and/or property losses that would reduce their premiums.

Principle 3: Dealing with equity and affordability issues. Any special treatment given to consumers at risk (e.g., low-income uninsured, high-risk moderate income groups, or inadequately insured individuals) should come from means-tested insurance vouchers financed by the federal government or at a state level through general taxes and not through subsidies generated by higher insurance premiums on lower-risk buyers.

Principle 4: Multi-year insurance. A multi-year policy provides stability of premiums since it prevents individuals from being reclassified into higher risk strata during the term of the contract. Such policies currently exist for life insurance and long-term care coverage (Abraham and Chiappori, Chapter 9 in this volume). 
In the case of property insurance, where only annual policies are currently marketed, a multi-year policy could be coupled with long-term loans for cost-effective hazard reduction measures. The homeowner would be rewarded for undertaking these investments, inasmuch as the yearly cost of the loan is likely to be less than the annual premium reduction. State insurance regulators would have to allow insurers to charge premiums that reflect the reduced risk for those who take the loans and higher premiums for those who do not.

Even before the ACA was passed, health insurance policies achieved multi-year premium stability by including guaranteed renewability at class average premiums as a policy feature. Under this arrangement, insurers promise not to single out those whose risk rises for selective premium increases. This gives the insurer an incentive to keep the insureds healthy, since the insurer is at risk for higher expenses that might be preventable. Guaranteed renewability also protects consumers from premium increases due to deterioration in their health.

Given that the federal government is the principal provider of flood coverage to homeowners, it should be feasible to require multi-year policies tied to the property, thus satisfying Principles 1 and 4. Given that many people cancel their policies if they have not suffered a loss, this requirement needs to be well enforced in the future. For premiums to reflect risk, FEMA needs to improve the accuracy of its flood maps as recommended by the Government Accountability Office (2004). FEMA's Map Modernization Program will result in maps prepared in digital format for 92 percent of the continental US population. Land development and natural changes to the landscape and/or to hydrologic systems require continuous map maintenance and updates. The National Research Council (2009) and the National Academy of Sciences are now undertaking a study of means-tested insurance vouchers to deal with equity and affordability issues (Principle 3).

The ACA for health insurance, passed only after a major legislative and legal battle, embodies Principles 1 and 3. Insurance offered to individuals and small groups through exchanges is to be subsidized with means-tested tax credits (Principle 3). The ACA mandates penalties on those who do not purchase insurance to encourage the purchase of catastrophic protection (Principle 1). However, the penalties are weak and may not be enough to induce low-risk people to purchase coverage. The generous subsidies in the ACA should be enough to motivate the purchase of coverage by lower income people who undertake deliberative thinking, but the 'outreach' (marketing) activities of the Health Insurance Marketplaces run by states or the federal government may also need to use insights from behavioral economics to address the problem of take-up of coverage; they need to 
frame the information they provide in a way that convinces people of the true loss probability and deters them from using the heuristics and biases discussed above. Specifically, it would be important to have a better understanding of why low-risk people who could have afforded insurance did not purchase it, and how they might be expected to change behavior as regulation increases their premiums but also imposes a mandate and markets coverage more aggressively.

The ACA does not adhere to Principle 2, as it permits only very limited risk rating of premiums (restricted primarily to location, age, and smoking behavior). Healthy younger people who are not eligible for generous subsidies will correctly regard the premiums they will be required to pay in the new regulated exchanges as high relative to the benefits they can expect to collect, and no amount of truthful outreach may convince them to buy. Even if the prospective buyers are healthy through good luck, not because of behavioral factors, they will not find insurance to be a rational purchase unless there were substantial penalties or subsidies. They may purchase the minimum coverage required, when they might have been eager to buy considerably more insurance if premiums were tailored to their risk. There is also some modest public subsidy of reinsurance to offset the cost to those with high lifetime risks. Principle 4 (multi-year pricing) is, as noted, already required for individual health insurance but the additional limits on risk-based pricing in the new legislation noted above may attenuate the value of the feature, since protection against premium increases has no value if people can pay low premiums even if they become higher risks.

Both laws exemplify much of what is needed to improve individual and insurer behavior. They are designed to move people's behavior from intuitive processes to more deliberative thinking with respect to LP-HC events. The contentious and continuing debate over both pieces of legislation, shows that the policy process does not automatically or easily generate such corrections; there needs to be persistent and dedicated political leadership based on skilled use of correct principles.

To be sure, both legislative proposals were directed at more than rectifying the mistakes by insurers, consumers, and state regulatory officials that arise from behavioral biases and simplified heuristics. They were also designed to reduce losses and alleviate the fiscal burden on governments. Unfortunately, some of the attempts to improve equity end up distorting insurance premiums and, in doing so, frustrate other features in the legislation that were designed to improve the decision making process. We feel that the guiding principles outlined above are linchpins for improving the choices of both insurers and insureds. 


\section{TOWARD A TAXONOMY OF GOVERNMENT INTERVENTIONS TO DEAL WITH INSURANCE ANOMALIES}

Property and health insurance are instructive cases for examining the rationale and design of effective government interventions, whether through insurance regulation, laws that provide mandates and/or subsidies, or nudges through reframing options that lead people to make better choices. The flood and health insurance legislation are at the aggressive end of the spectrum as they involve heavy regulation of offerings and required coverage. Is this kind of heavy weaponry appropriate for other insurance anomalies that arise from intuitive thinking?

We hypothesize that there are three features that suggest public intervention on this scale is appropriate.

Feature 1: Anomalous behavior that involves under-purchase rather than over-purchase of insurance or protection.

Feature 2: Anomalous behavior that causes large harm to a population's wellbeing that is of concern to others for any reason - altruistic, social welfare, or ethical.

Feature 3: Settings where individuals have difficulty taking steps to reduce their risk.

Health insurance for lower income people fits all three of these characteristics. Many low-income people do not have insurance, and the absence of coverage can cause serious harm to health if it inhibits the use of effective care. These families' health levels and (perhaps) their financial status are of concern to their fellow citizens. Individuals are sometimes reluctant to undertake preventive health measures, such as their failure to take statin drugs after a heart attack, even when insurance fully covers the cost (Choudhry, Avorn, and Glynn 2011) or not having their children vaccinated against contagious disease.

Lower income homeowners present a similar case. Many of these families are uninsured because they cannot afford coverage. Few individuals in high-risk areas voluntarily invest in measures to reduce their losses from future disasters (Kunreuther, Meyer, and Michel-Kerjan 2013). If they suffer serious damage from a severe disaster, the public is concerned with their plights and there is sympathy (if not funding) so these disaster victims can remain in their current location rather than moving to a safer spot.

When one or more of these three features is absent, the case for public intervention of the type embodied in the ACA or Biggert-Waters is weaker. 
We are usually most concerned about people whose use or consumption of some key good falls below some ideal level, and less concerned when it rises above the desirable amount (Feature 1). Purchasing overpriced warranties illustrates the case where there is an absence of all of the above features, since the impact on the person buying the warranty and others is likely to be minimal. In cases such as these, intervention usually involves warning consumers, providing them with better information and offering them a chance to get their money back after second thoughts. We conclude that in situations where the consequence of excessive insurance is just wasted money rather than physical impairment or significant reduction in assets or wealth, it may not be worth the effort for governments to try to correct such modest mistakes. Indeed, the maximum loss from mistakenly buying insurance that is overpriced or unneeded is simply the cost of the insurance. In contrast, the loss in welfare from not buying needed insurance could be very high indeed.

Risks (of any type) that primarily affect people in higher income brackets, or risks that affect people across the income spectrum but that can be avoided are also less appropriate candidates for aggressive intervention, even if the consequences of under-purchasing insurance are large. In these cases, concern by others (Feature 2) is lacking. For example, if Warren Buffett, famously frugal, had decided not to buy health insurance before he was 65 , there would not be a strong public policy interest in getting him to do so. There are no health insurance subsidies for the not-very-poor (households with incomes over 400 percent of poverty), though there is a mild penalty associated with not purchasing coverage for the purpose of maintaining the risk pool so as to subsidize high risks as a matter of social concern (Feature 2).

Another example commonly cited as an insurance anomaly is the underpurchase of annuities. People with accumulated assets should be interested in converting their wealth to annuities so they can maintain their standard of living for as long as they live. There were proposals in the early days of the Obama administration from a Treasury official to reframe choices people make when they retire so taking an annuity was the default option for 401(k) accounts (Gale et al. 2008). And there is a great deal of academic literature on the subject that also points to framing as the cause of the problem - without explaining why the correct framing does not prevail in a competitive market (Kunreuther, Pauly, and McMorrow 2013).

The primary reasons for the lack of interest or enthusiasm for encouraging the purchase of annuities is that this is a problem facing the upper middle class elderly, who are not a population of major social concern. Almost everyone has a compulsory annuity in the form of Social Security, and its benefits are usually enough to keep people in all income classes 
above the poverty line (even if just barely). Utilizing some of the limited stock of political capital to mobilize government to solve a problem that affects primarily people with six-figure incomes does not have any traction.

The other example of under-protection is in the area of life insurance. Although most people do have some life insurance protection, they may buy too little and often make the mistake of dropping their coverage soon after purchasing it because they feel the premiums are too high given budget constraints (Gottlieb and Smetters 2012). Here again, life insurance is largely a concern of the middle class and above, and largely protects the bequests they leave to their heirs so there is little concern by others (that is, Feature 2 is lacking) and hence no public intervention. The availability of Social Security death and survivors' benefits further attenuates the public policy motivation to deal with this problem beyond applying band-aids in the form of mandatory disclosure of information.

Over-purchasing insurance is another story. Sometimes people do so for good reason. For example, the partial payment of group medical and dental insurance by employers due to the tax advantages on group health insurance suggests that one should have more insurance than one would otherwise purchase.

On the other hand, many people purchase more coverage than would be implied by System 2 thinking. The most prevalent case is deductible aversion: the desire for low deductibles (Sydnor 2010; Kunreuther, Pauly, and McMorrow 2013). By undertaking deliberative thinking, one should realize that the savings (premium reduction) associated with a high deductible (on automobile, homeowners', or individual health insurance) more than compensate for the additional payments should one suffer a loss.

There are many hypotheses about why people make this mistake: They overestimate the chances of collecting on the lower deductible, they want to increase the chances of collecting on their policy so they can view insurance as a positive investment, or they just want peace of mind and freedom from regret. There are some serious puzzles in the literature regarding this anomaly. For example, many individuals do not make a claim on their policy when their losses exceed the deductible, which suggests they should have taken a higher one (Braun et al. 2006). If insurance markets are competitive, how can overpriced low deductible plans survive? Here again, there are few rules and few advocates for public policy to deal with this problem because purchasing a low deductible does not satisfy any of the three features listed above.

Then there are some cases where insurance or insurance-like arrangements can be bundled with other products. Individuals often go for the 
bundle even when portions of the package are overpriced. Insurance for rental cars, appliance warranties, or the purchase of flight insurance all exhibit this characteristic. We could not find a single public policy initiative actually undertaken in the United States intended to discourage this behavior when these examples show that individuals clearly misunderstand the purposes of insurance (Liebman and Zeckhauser 2008). (This is not to deny that such interventions are sometimes advocated for some countries (Competition Commission 2003).) These mistakes in consumer purchasing so far do not seem to rise to the level of social concern because they normally do not relate to behaviors that are of a concern to others (Feature 2). They also do not satisfy the characteristics of Features 1 and 3.

More specifically, there are almost no regulations beyond standard consumer protection rules that are intended to affect the usual cases of anomalous over-purchase. However, there are some exceptions. For example, the state of California does require disclosure that the driver's own automobile insurance normally applies to a rental car so that purchase of additional insurance to cover the collision damage waiver may not be needed. ${ }^{2}$

There is usually no requirement that sellers of automobiles or appliances that provide warranties hold reserves to assure payment of liabilities under those warranties should a manufacturer go bankrupt, although there are reserves and other insurance-type regulations for firms that sell 'freestanding' warranties. (The United Kingdom does require a 'cooling off' period after a warranty is purchased during which the purchase can be canceled (Warranty Week 2004).) And there are no rules to forbid the purchase or warn consumers of the rationale for not purchasing low deductible insurance if it carries a very high incremental premium relative to the actuarial value of the additional coverage.

There have been some attempts by the US Treasury to encourage the purchase of private annuities by workers with 401(k) accounts (Lieber 2010), as noted above. In February 2012 the rules for 401(k)s were changed to make it easier for employers to offer their own annuity option to employees who might wish to convert their 401(k), and to exempt payments for the 'longevity insurance' form of an annuity (one in which annuity payments do not start until an older age) from the minimum distribution rules for IRA balances (Ellis 2012). For life insurance, there are no regulations regarding how premiums can be set for multi-year term insurance.

\footnotetext{
2 See www.ehow.com/facts_5753168_california-regulations-rental-car-insura nce.html.
} 
To summarize, in a world where the intrinsic imperfection of government intervention is both more in evidence and more frequently acknowledged than in the past, there is little call for policies designed to deal with insurance against events that mostly affect moderate risks for people in the higher income brackets.

\section{INSURANCE WHEN BAD THINGS CAN HAPPEN, BUT NOT OFTEN}

As already noted, insurers have had a difficult time maintaining a steady and reliable supply of reasonably priced coverage against losses that are rare but correlated, with terrorism and natural disasters as two examples. Even if insurers examine past data in a systematic manner, there can still be a problem caused by imprecision in estimating future periods' loss probabilities when events are rare and the world is changing over time.

Consider the easy case where science and past information are sufficient to convince buyers of insurance, managers of insurance firms and insurance regulators of the true probability of a loss-producing event. To illustrate, suppose one estimates that the likelihood of a flood next year is 1 in 100 and that this probability will remain constant for the foreseeable future. Then there will be no disagreement by the relevant parties as to how to estimate the likelihood of a future flood occurring. There are some cases that satisfy this condition where our mathematical models are so well validated and so unambiguous and convincing that experts are in agreement, like the return of Halley's Comet.

But what if it has been 50 years since the last Big Flood, and we know that the world is changing? For example, there are data on global warming and its potential impact on sea level rise, but with considerable uncertainty surrounding these estimates. In cases such as this, we cannot rely on either recent data and/or theoretical models to provide an assured, defensible, and unambiguous estimate of the loss probability.

If insurers charge premiums for windstorm or flood insurance based on a low but positive probability of a damaging event, it is likely that there will be no disaster for years, in which case the insurer will accumulate enormous underwriting profits. These reserves will be needed to pay claims when a serious disaster does occur. But the general public and regulators may become uncomfortable upon learning that the insurer's surplus has increased significantly from a series of disaster-free years, claiming that the premiums being charged are too high.

As discussed earlier, Florida addressed this issue by forming a statebacked insurer (Citizens Corporation) that charges subsidized premiums. 
Critics have rightly noted that this arrangement potentially puts all Florida taxpayers at risk should there be a severe hurricane and Citizens does not have enough surplus to pay all the claims. In other words, an intense minority of (often high-wealth) property owners residing in hurricaneprone areas are being highly subsidized by all the residents in Florida.

There is another alternative: mutual insurance. Under this arrangement, if one subsidizes the premiums, everyone who purchases the insurance will be assessed if reserves and premiums are inadequate when a disaster occurs. Collecting this assessment ex post may be difficult, so an alternative (in effect) is to charge higher than actuarially fair premiums but tell purchasers that a portion of their payment is being held in a fund that they personally own. Dividends can be declared if the event does turn out to be rarer than originally anticipated. In this arrangement, policyholders bear the full cost of their coverage if an event occurs, but get money back if it does not. In effect, they are protected, with insurance sold at a moderate net price whether the probability turns out to be high or low (Pauly, Kunreuther, and Vaupel 1984).

\section{SUPPLEMENTING THE GUIDING PRINCIPLES IN ADDRESSING THESE CHALLENGES}

The four guiding principles can be supplemented by utilizing approaches that alleviate some of the biases that constitute intuitive (System 1) thinking.

In the case of buyers, we recommend that when presenting information on the likelihood of an LP-HC event occurring, one stretches the time horizon. Rather than saying that there is a 1 in 100 chance next year of damage from a severe hurricane, reframe the same probability by saying that the chance that one's property will be damaged from a hurricane in the next 25 years is greater than 1 in 5. Empirical studies have shown that data presented in this fashion raises the probability that individuals will take protective measures (Slovic, Fischhoff, and Lichtenstein 1978; Weinstein, Kolb, and Goldstein 1996).

One of the biggest challenges is to convince consumers that if they do not suffer losses from a disaster or incur health-related expenditures next year, the purchase of insurance was not a waste of money. It is extremely difficult to get the message across that those at risk should celebrate not having collected on their insurance policy. One way to do this is to remind people that something serious could happen to them next year, so they should not cancel their insurance policy without good reason.

Finally, providing transparent information related to the rationale for 
insurance should go a long way to helping the general public better understand this policy tool. Insurance can then fulfill the roles it is designed to play: reducing future losses and financially protecting those at risk.

\section{REFERENCES}

111th Congress. 2010. H.R. 3590 (111th): Patient Protection and Affordable Care Act. Text as of August 25, 2010. Washington, DC: United States Government Printing Office (GOP). www.govtrack.us/congress/bills/111/hr3590/text (accessed September 27, 2013).

112th Congress. 2012. H.R. 4348 (112th): MAP-21. Title II - Flood Insurance. Text as of September 29, 2012. Washington, DC: United States Government Printing Office (GOP). www.govtrack.us/congress/bills/112/hr4348/text (accessed September 27, 2013).

Arrow, K. 1971. Essays in the Theory of Risk Bearing. Chicago, IL: Markham.

Braun, M., P. Fader, E. Bradlow, and H. Kunreuther. 2006. Modeling the 'Pseudodeductible' in Homeowners Insurance. Management Science 52: 1258-72.

Choudhry, N., J. Avorn, and R. Glynn. 2011. Eliminating Copayments for Patients After Myocardial Infarction Improves Adherence and Some Outcomes. New England Journal of Medicine 365: 2088-97.

Competition Commission. 2003. Extended Warranties on Domestic Electrical Goods: A Report on the Supply of Extended Warranties on Domestic Electrical Goods within the UK - Volumes 1, 2 and 3. Available at http://webarchive.nationalarchives.gov.uk/+/http:// www.competition-commission.org.uk/rep_pub/reports/2003/485xwars.htm\#summary (accessed July 25, 2014).

Cutler, D. M., and R. Zeckhauser. 2004. Extending the Theory to Meet the Practice of Insurance. In R. Herring and R. E. Litan, eds., Brookings-Wharton Papers on Financial Services. Washington, DC: Brookings Institution Press, pp. 1-53.

Ellis, B. 2012. Obama's Latest Retirement Rescue Plan: Annuities. Available at http:// money.cnn.com/2012/02/02/pf/rules_retirement_annuities/ (accessed March 2, 2015).

Gale, W. G., J. M. Iwry, D. C. John, and L. Walker. 2008. Increasing Annuitization in 401(k) Plans With Automatic Trial Income. The Hamilton Project, Discussion Paper 2008-02. Washington, DC: The Brookings Institution.

Gottlieb, D., and K. Smetters. 2012. Narrow Framing and Life Insurance. NBER Working Paper No. 18601. Cambridge, MA: National Bureau of Economic Research.

Government Accountability Office (GAO). 2004. Flood Map Modernization Program Shows Promise, but Challenges Remain. Washington, DC: GAO04-417.

Jaffee, D., and T. Russell. 2003. Market Under Stress: The Case of Extreme Event Insurance. In R. Arnott, B. Greenwald, R. Kanbur and B. Nalebuff, eds., Economics for an Imperfect World: Essays in Honor of Joseph E. Stiglitz. Cambridge, MA: MIT Press.

Johnson, E., and D. Goldstein. 2003. Do Defaults Save Lives? Science 302: 1338-9.

Kahneman, D. 2011. Thinking, Fast and Slow. New York, NY: Farrar, Straus and Giroux.

Kunreuther, H., R. J. Meyer, and E. Michel-Kerjan. 2013. Overcoming Decision Biases to Reduce Losses from Natural Catastrophes. In E. Shafir, ed., Behavioral Foundations of Policy. Princeton, NJ: Princeton University Press, chapter 23, pp. 398-413.

Kunreuther, H., and E. Michel-Kerjan. 2011. At War with the Weather. Cambridge, MA: MIT Press.

Kunreuther, H., M. V. Pauly, and S. McMorrow. 2013. Insurance and Behavioral Economics: Improving Decisions in the Most Misunderstood Industry. New York, NY: Cambridge University Press.

Lieber, R. 2010. The Unloved Annuity Gets a Hug from Obama. New York Times, January 28.

Liebman, J., and R. Zeckhauser. 2008. Simple Humans, Complex Insurance, Subtle Subsidies. In H. Aaron and L. Burman, eds., Using Taxes to Reform Health Insurance: Pitfalls and Promises. Washington, DC: Brookings Institution, pp. 230-62. 
Madrian, B., and D. Shea. 2001. The Power of Suggestion: Inertia in 401(k) Participation and Savings Behavior. Quarterly Journal of Economics 116: 1149-225.

Michel-Kerjan, E., S. Lemoyne de Forges, and H. Kunreuther. 2012. Policy Tenure Under the U.S. National Flood Insurance Program. Risk Analysis 32(4): 644-58.

Musco, T., and B. Somers. 2012. Under the Affordable Care Act, 105 million Americans No Longer Face Lifetime Limits on Benefits. ASPE Issue Brief. US Department of Health and Human Services. Available at http://aspe.hhs.gov/health/reports/2012/lifetimelimits/ ib.shtml (accessed February 13, 2015).

National Research Council. 2009. Mapping the Zone: Improving Flood Map Accuracy. Washington, DC: The National Academies Press.

National Research Council. 2015. Affordability of National Flood Insurance Program Premiums - Report 1. Washington, DC: The National Academies Press.

Organisation for Economic Co-Operation and Development (OECD). 2008. Financial Management of Large-Scale Catastrophes. Policy Issues in Insurance, No. 12. Paris: OECD Publishing. DOI:10.1787/9789264041516-en (accessed September 27, 2013).

Pauly, M. V., H. Kunreuther, and J. Vaupel. 1984. Public Protection Against Misperceived Risks: Insights from Positive Political Economy. Public Choice 43(1): 45-64.

PricewaterhouseCoopers. 2009. The Impact of Lifetime Limits. A Study Prepared for the National Hemophilia Foundation on Behalf of the Raise The Caps Coalition. Available at www.amcp.org/WorkArea/DownloadAsset.aspx?id=12211 (accessed March 2, 2015).

Raiffa, H. 1968. Decision Analysis: Introductory Lectures on Choices Under Uncertainty. Reading, MA: Addison-Wesley.

Roy, A. D. 1952. Safety First and the Holding of Assets. Econometrica: Journal of the Econometric Society, 431-49.

Shavell, S. 1979. On Moral Hazard and Insurance. Quarterly Journal of Economics 93(4): $541-62$.

Slovic, P., B. Fischhoff, and S. Lichtenstein. 1978. Accident Probabilities and Seat Belt Usage: A Psychological Perspective. Accident Analysis and Prevention 10: 281-5.

Smetters, K. 2004. Insuring Against Terrorism: The Policy Challenge. In R. Litan and R. Herring, eds., Brookings-Wharton Papers on Financial Services, Washington, DC: Brookings Institution Press, pp. 139-82.

Stone, J. 1973. A Theory of Capacity and the Insurance of Catastrophic Risks: Part I and Part II. Journal of Risk and Insurance 40: 231-43, 339-55.

Sydnor, J. 2010. (Over)Insuring Modest Risks. American Economic Journal: Applied Economics 2: 177-99.

Thaler, R. H., and S. Benartzi. 2004. Save More Tomorrow: Using Behavioral Economics to Increase Employee Savings. Journal of Political Economy 112: S164-87.

Thaler, R. H., and C. R. Sunstein. 2008. Nudge: Improving Decisions about Health, Wealth, and Happiness. New Haven, CT: Yale University Press.

Tversky, A., and D. Kahneman. 1973. Availability: A Heuristic for Judging Frequency and Probability. Cognitive Psychology 5(1): 207-33.

von Neumann, J. and O. Morgenstern. 1944. Theory of Games and Economic Behavior. Princeton, NJ: Princeton University Press.

Warranty Week. 2004. 'Extended Warranties in the UK' January 20. Available at www.war rantyweek.com/archive/ww20040120.html (accessed February 13, 2015).

Weinstein, N., K. Kolb, and B. Goldstein. 1996. Using Time Intervals Between Expected Events to Communicate Risk Magnitudes. Risk Analysis 16: 305-8.

Wharton Risk Center. 2005. TRIA and Beyond: Terrorism Risk Financing in the U.S. Philadelphia: The Wharton School, University of Pennsylvania. 